\title{
STEEL FRAMED STRUCTURES SUBJECTED TO THE COMBINED EFFECTS OF BLAST AND FIRE- PART 2: CASE STUDY
}

\author{
H.X. Yu and J.Y. Richard Liew* \\ * Department of Civil Engineering, National University of Singapore, \\ BLK E1A, 1 Engineering Drive 2, Singapore 11757. \\ Email: cveljy@nus.edu.sg
}

\begin{abstract}
Design of public infrastructure against terrorist attack has become a rising concern to reduce the level of damage to properties and the loss of life. Some of the terrorist acts take the form of blast followed by fire causing catastrophic failure of the structure. This two-part paper aims to study the response of steel framed structures subjected to the combined effect of blast and fire. In Part 1 of the companion paper, an overview is made on the methods for determining the blast load and finite element techniques for dynamic and impulsive analysis. In this paper, a typical five-storey steel framed building with concrete slab system and external masonry cladding, subjecting to mid-scale bomb and then followed by fire, is analyzed using a dynamic analysis software, LS-DYNA. A sequential procedure for a dynamic blast-fire analysis is proposed. The effect of blast on active and passive fire protection systems is assessed. The local and lateral-torsional buckling failure modes associated with members subjected to the combined effect of blast and fire are identified in contrast with the failure modes predicted based on fire analysis alone. Collapse analysis showed that blast load could affect on the performance of passive and active fire protection system, and the blast damaged structure possesses very little resistance to fire.
\end{abstract}

Keywords: blast, collapse, fire, dynamic analysis, steel frame, strain rate effect, temperature

\section{STRUCTURAL LAYOUT}

A 3 x 4-bay and 5-story steel building with member sizes and building layout plan as shown in Figure 1 has been constructed. The storey height is $4.0 \mathrm{~m}$. Grade S275 steel is used for all steel members, and grade C30 normal weight concrete is used for the slab of $120 \mathrm{~mm}$ thick. The floor load at the accidental limit state is $6.25 \mathrm{kN} / \mathrm{m}^{2}$. The external walls are assumed to be masonry wall of $150 \mathrm{~mm}$ thickness. Rigid and full strength beam-column connections are assumed and the frame is fully continuous to [provide a progressive collapse resistant design. One member size B1 is used for all beams in the $\mathrm{x}$ direction and one beam size $\mathrm{B} 2$ is chosen for all beams in the $\mathrm{y}$ direction. For the first four stories, one column size $\mathrm{C} 1$ is used for all the internal columns, and one column size $\mathrm{C} 2$ is used for all the edge and corner columns. For the top floor, a smaller column size is used, but the beam sizes remained the same. The members' sizes are tabulated in Figure 1. All the beams are assumed to be in full composite action with the concrete slabs. 

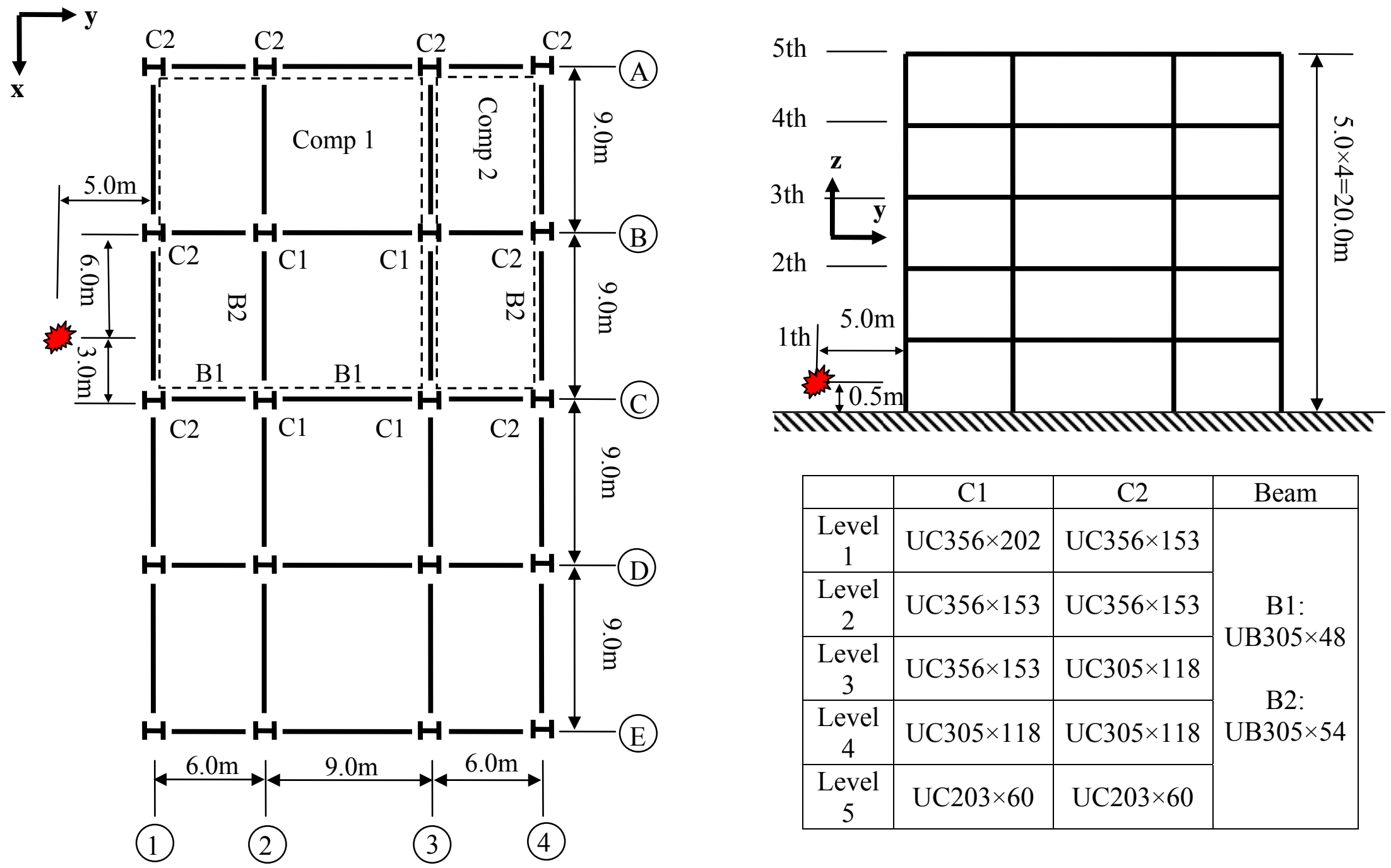

\begin{tabular}{|c|c|c|c|}
\hline & $\mathrm{C} 1$ & $\mathrm{C} 2$ & Beam \\
\hline $\begin{array}{c}\text { Level } \\
1\end{array}$ & $\mathrm{UC} 356 \times 202$ & $\mathrm{UC} 356 \times 153$ & \\
\cline { 1 - 3 } $\begin{array}{c}\text { Level } \\
2\end{array}$ & $\mathrm{UC} 356 \times 153$ & $\mathrm{UC} 356 \times 153$ & $\mathrm{~B} 1:$ \\
\cline { 1 - 2 } $\begin{array}{c}\text { Level } \\
3\end{array}$ & $\mathrm{UC} 356 \times 153$ & $\mathrm{UC} 305 \times 118$ & $\mathrm{UB} 305 \times 48$ \\
\cline { 1 - 3 } $\begin{array}{c}\text { Level } \\
4\end{array}$ & $\mathrm{UC} 305 \times 118$ & $\mathrm{UC} 305 \times 118$ & $\mathrm{UB} 305 \times 54$ \\
\cline { 1 - 2 } $\begin{array}{c}\text { Level } \\
5\end{array}$ & $\mathrm{UC} 203 \times 60$ & $\mathrm{UC} 203 \times 60$ & \\
\hline
\end{tabular}

Figure 1. The layout and member sizes of the frame 


\section{FIRE SAFETY DESIGN}

The steel frame considered here is a common office building with regular layouts. Fire safety design of structures generally follows 3 main steps: 1) determine the temperature development in a fire compartment by assuming a proper fire scenario, 2) calculate the temperature development in the structural members using heat transfer analysis, and 3) determine the fire resistance of the structural members and ensure that the resistance is greater than the effects due to the applied loads evaluated in the fire limit state. Alternatively, a limiting temperature approach may also be used to ensure that it is greater than the maximum temperature attained in the fire.

In the present study, the temperature developed in a fire compartment is calculated based on Eurocode parametric fire [1]. The limiting temperatures of all members are calculated according to the simplified design method in BS5950: Part 8 [2]. The most important factors in determine the room temperature in a fire compartment is the thermal property of the enclosure surfaces, dimensions of the room, fire load and ventilation factor. The fire can be fuel controlled or ventilation controlled. Fuel controlled fire is characterized by rapid burning and rapid decay. Ventilation controlled fire is slower process in which accumulation and dissipation of heat takes a longer time. Liew and Ma [3] have discussed the effects of each factor.

Two possible fire compartments/scenarios are assumed (indicated by the dashed lines) in view of the symmetry of the floor plan as shown in Figure 1. The fire compartments are designated by Comp 1, Comp 2. Assumptions for calculating the parametric fires are listed below:

a. This is a typical office building with characteristic floor load $q_{f, k}=511 \mathrm{MJ} / \mathrm{m}^{2}$

b. Referring to equation (1) of Part I of the companion paper, the effect of active fire fighting measure is $\delta_{n}=\sum_{i=1}^{n} \delta_{n i}=0.6$.

c. At each level, there are continuous window openings on the front and back walls with a height of $2 \mathrm{~m}$ (see Figure 2).

d. All the compartment walls are assumed to be masonry with the thermal absorptivity $b=\sqrt{\rho C \lambda}=1239$.

e. When passive fire protection is specified, sprayed mineral fiber is adopted.

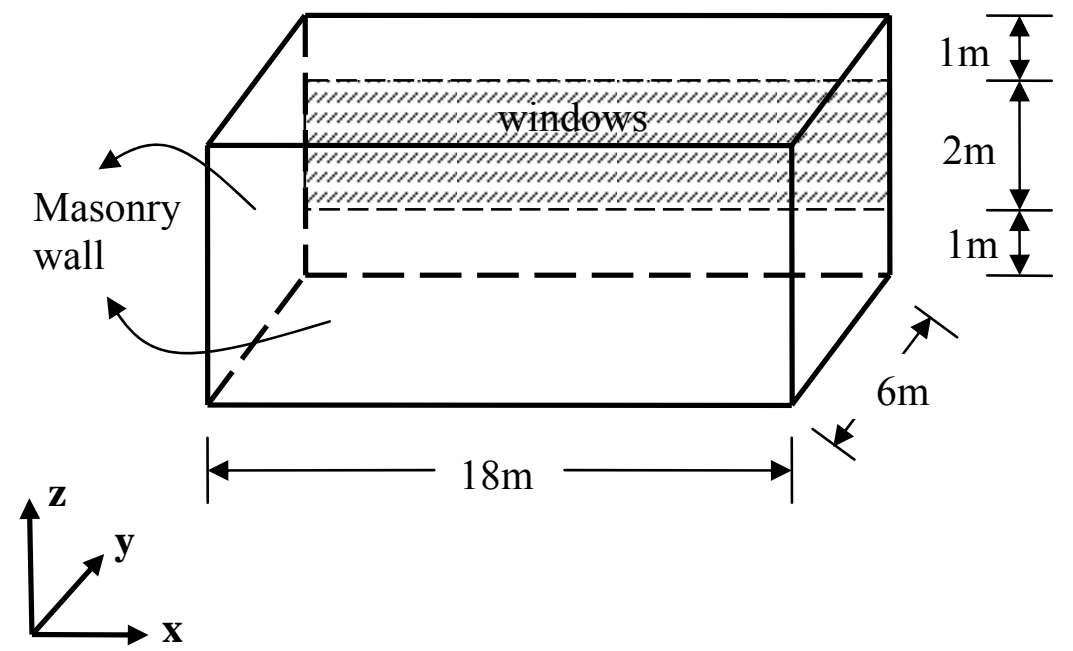

Figure 2(a) Fire Compartment 2 


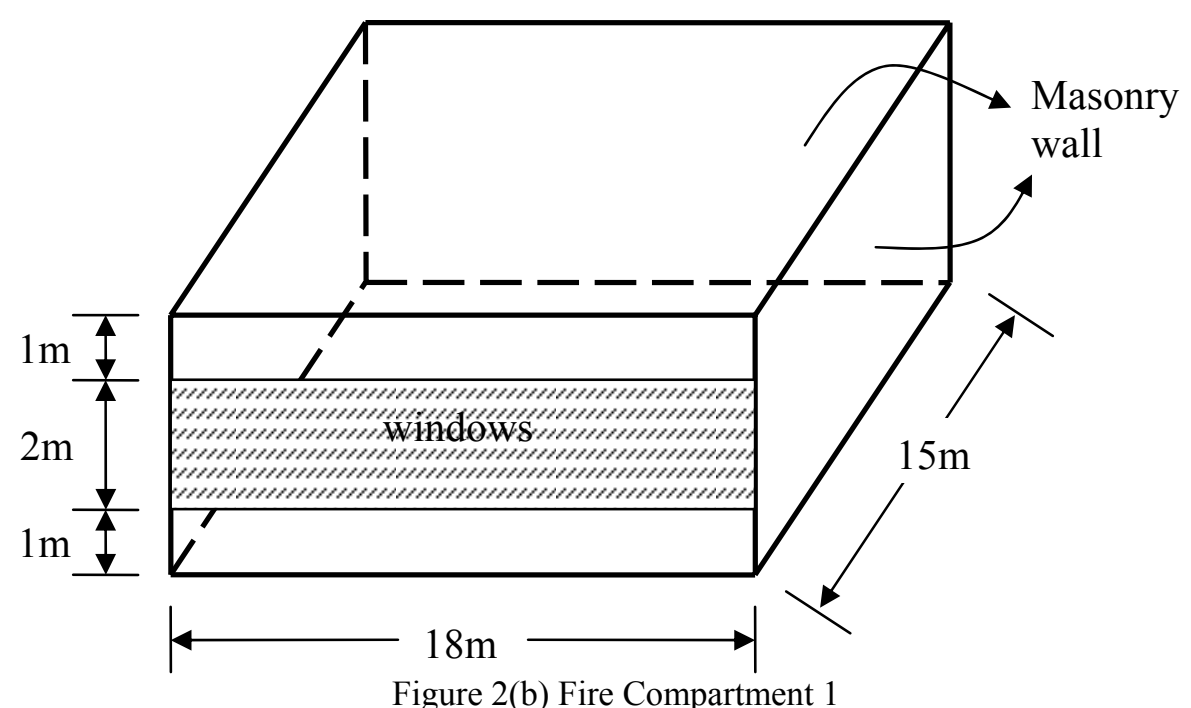

Figure 2. Dimensions and window openings for the fire compartments

The fire load density, $\mathrm{q}_{\mathrm{t}, \mathrm{d}}$, and ventilation factor, $\mathrm{O}$, are $123.6 \mathrm{MJ} / \mathrm{m}^{2}$ and 0.063 for Comp 1 and $97.4 \mathrm{MJ} / \mathrm{m}^{2}$ and 0.063 for Comp 2, respectively. The design temperature-time curves for Comp 1 and Comp 2 are determined in accordance with EC1:Part1.2 [1] as shown in Figure 3. The fire in Comp 1 is more severe than Comp 2 in terms of the peak temperature and rate of heating. Therefore, the structural members sharing the same the boundary of Comp 1 and Comp 2 are designed according to the fire temperature in Comp 1.

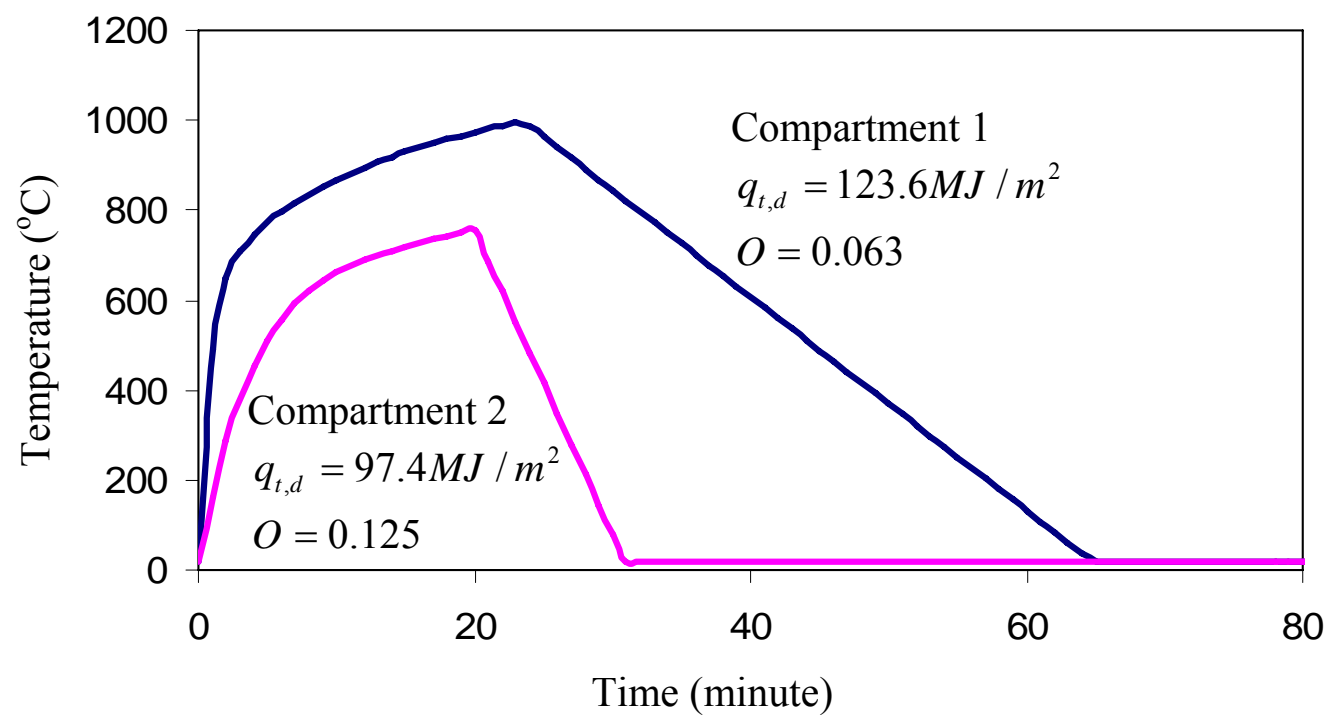

Figure. 3. Design fire for compartments 1 and 2.

Calculation of fire protections for structural members is in accordance with the procedure given in BS 5950: Part 8 [2] and the results are shown in Table 1. $\mu$ is the load ratio of the member defined as the ratio of the effect of load at fire limit state to its capacity. The limiting temperature $\mathrm{T}_{\lim }$ is calculated from the utilization factor. $T_{\text {up }}$ and $T_{p}$ are the maximum temperature in the steel member without and with fire protection. Passive fire protection is required when $T_{u p}>T_{\lim } \cdot t_{\mathrm{c}}$ is the thickness of passive fire protection. To meet the safety requirement, it requires that $T_{p}<T_{\lim }$. 
The results from fire safety design are summarized as follows:

(1) All beams are fire protected by $20 \mathrm{~mm}$ thick fibre mineral spray.

(2) Columns on Grid Line 4 can be left unprotected, the interior columns at the fifth floor need $15 \mathrm{~mm}$ fire protection because of the higher load ratio as shown in Table 2. All the other columns need only $10 \mathrm{~mm}$ fire protection.

Table 2. Calculation of the passive fire protection for all steel members

\begin{tabular}{|c|c|c|c|c|c|}
\hline Section & Level 1 & Level 2 & Level 3 & Level 4 & Level 5 \\
\hline B1 & $\mu=0.673$ & $\mathrm{~T}_{\mathrm{lim}}=598^{\circ} \mathrm{C}$; & $\mathrm{T}_{\text {up }}=1009^{\circ} \mathrm{C} ;$ & $\mathrm{t}_{\mathrm{c}}=20 \mathrm{~mm} ;$ & $\mathrm{T}_{\mathrm{p}}=524^{\circ} \mathrm{C}$ \\
\hline $\mathrm{B} 2$ & $\mu=0.709$ & $\mathrm{~T}_{\text {lim }}=550^{\circ} \mathrm{C}$ & $\mathrm{T}_{\text {up }}=1009^{\circ} \mathrm{C}$ & $\mathrm{t}_{\mathrm{c}}=20 \mathrm{~mm}$ & $\mathrm{~T}_{\mathrm{p}}=524^{\circ} \mathrm{C}$ \\
\hline C1 (Comp 1) & $\begin{array}{l}\mu=0.206 \\
\mathrm{~T}_{\text {lim }}=707^{\circ} \mathrm{C} \\
\mathrm{T}_{\text {up }}=988^{\circ} \mathrm{C} \\
\mathrm{t}_{\mathrm{c}}=10 \mathrm{~mm} \\
\mathrm{~T}_{\mathrm{p}}=576^{\circ} \mathrm{C}\end{array}$ & $\begin{array}{l}\mu=0.165 \\
\mathrm{~T}_{\text {lim }}=741^{\circ} \mathrm{C} \\
\mathrm{T}_{\text {up }}=988^{\circ} \mathrm{C} \\
\mathrm{t}_{\mathrm{c}}=10 \mathrm{~mm} \\
\mathrm{~T}_{\mathrm{p}}=576^{\circ} \mathrm{C}\end{array}$ & $\begin{array}{l}\mu=0.164 \\
\mathrm{~T}_{\text {lim }}=741^{\circ} \mathrm{C} \\
\mathrm{T}_{\text {up }}=1000^{\circ} \mathrm{C} \\
\mathrm{t}_{\mathrm{c}}=10 \mathrm{~mm} \\
\mathrm{~T}_{\mathrm{p}}=631^{\circ} \mathrm{C}\end{array}$ & $\begin{array}{l}\mu=0.111 \\
\mathrm{~T}_{\text {lim }}=790^{\circ} \mathrm{C} \\
\mathrm{T}_{\mathrm{up}}=1000^{\circ} \mathrm{C} \\
\mathrm{t}_{\mathrm{c}}=10 \mathrm{~mm} \\
\mathrm{~T}_{\mathrm{p}}=631^{\circ} \mathrm{C}\end{array}$ & $\begin{array}{l}\mu=0.120 \\
\mathrm{~T}_{\text {lim }}=782^{\circ} \mathrm{C} \\
\mathrm{T}_{\text {up }}=1005^{\circ} \mathrm{C} \\
\mathrm{t}_{\mathrm{c}}=10 \mathrm{~mm} \\
\mathrm{~T}_{\mathrm{p}}=675^{\circ} \mathrm{C}\end{array}$ \\
\hline C1 (Comp 2) & $\begin{array}{l}\mu=0.206 \\
\mathrm{~T}_{\text {lim }}=707^{\circ} \mathrm{C} \\
\mathrm{T}_{\text {up }}=663^{\circ} \mathrm{C} \\
\mathrm{t}_{\mathrm{c}}=\text { none }\end{array}$ & $\begin{array}{l}\mu=0.165 \\
\mathrm{~T}_{\text {lim }}=741^{\circ} \mathrm{C} \\
\mathrm{T}_{\text {up }}=663{ }^{\circ} \mathrm{C} \\
\mathrm{t}_{\mathrm{c}}=\text { none }\end{array}$ & $\begin{array}{l}\mu=0.164 \\
\mathrm{~T}_{\text {lim }}=741^{\circ} \mathrm{C} \\
\mathrm{T}_{\text {up }}=688^{\circ} \mathrm{C} \\
\mathrm{t}_{\mathrm{c}}=\text { none }\end{array}$ & $\begin{array}{l}\mu=0.111 \\
\mathrm{~T}_{\text {lim }}=790^{\circ} \mathrm{C} \\
\mathrm{T}_{\text {up }}=688^{\circ} \mathrm{C} \\
\mathrm{t}_{\mathrm{c}}=\text { none }\end{array}$ & $\begin{array}{l}\mu=0.120 \\
\mathrm{~T}_{\text {lim }}=782^{\circ} \mathrm{C} \\
\mathrm{T}_{\text {up }}=706^{\circ} \mathrm{C} \\
\mathrm{t}_{\mathrm{c}}=\text { none }\end{array}$ \\
\hline C2 (Comp 1) & $\begin{array}{l}\mu=0.306 \\
\mathrm{~T}_{\text {lim }}=659^{\circ} \mathrm{C} \\
\mathrm{T}_{\text {up }}=982^{\circ} \mathrm{C} \\
\mathrm{t}_{\mathrm{c}}=10 \mathrm{~mm} \\
\mathrm{~T}_{\mathrm{p}}=561^{\circ} \mathrm{C}\end{array}$ & $\begin{array}{l}\mu=0.324 \\
\mathrm{~T}_{\text {lim }}=642^{\circ} \mathrm{C} \\
\mathrm{T}_{\text {up }}=1000^{\circ} \mathrm{C} \\
\mathrm{t}_{\mathrm{c}}=10 \mathrm{~mm} \\
\mathrm{~T}_{\mathrm{p}}=631^{\circ} \mathrm{C}\end{array}$ & $\begin{array}{l}\mu=0.243 \\
\mathrm{~T}_{\text {lim }}=686^{\circ} \mathrm{C} \\
\mathrm{T}_{\text {up }}=1000^{\circ} \mathrm{C} \\
\mathrm{t}_{\mathrm{c}}=10 \mathrm{~mm} \\
\mathrm{~T}_{\mathrm{p}}=631^{\circ} \mathrm{C}\end{array}$ & $\begin{array}{l}\mu=0.214 \\
\mathrm{~T}_{\text {lim }}=702^{\circ} \mathrm{C} \\
\mathrm{T}_{\text {up }}=1003^{\circ} \mathrm{C} \\
\mathrm{t}_{\mathrm{c}}=10 \mathrm{~mm} \\
\mathrm{~T}_{\mathrm{p}}=654^{\circ} \mathrm{C}\end{array}$ & $\begin{array}{l}\mu=0.224 \\
\mathrm{~T}_{\text {lim }}=697^{\circ} \mathrm{C} \\
\mathrm{T}_{\text {up }}=1009^{\circ} \mathrm{C} \\
\mathrm{t}_{\mathrm{c}}=15 \mathrm{~mm} \\
\mathrm{~T}_{\mathrm{p}}=610^{\circ} \mathrm{C}\end{array}$ \\
\hline
\end{tabular}

\section{FINITE ELEMENT MODELLING}

\subsection{Modeling Technique}

The building frame consists of three main structural components: steel beams and columns, floor slab and external cladding. The steel beams and columns are major load-bearing members and they must be designed to provide adequate resistance to ensure overall stability and strength. The presence of floor slab is important to ensure adequate diaphragm action to ensure that the whole framework acts together in resisting the localized lateral forces generated by the blast load. External cladding is modeled so that to calculate the distribution of blast loading on the building and its deformation pattern is used to judge the damage caused by the blast. Both the slabs and walls are modeled by shell elements. For the steel members, the importance of refined modeling using shell elements has been discussed in the companion paper. Therefore, it was decided that the FEM model for the whole building should be constructed using shell elements. The connection details are ignored. Beams and columns are fully coupled at the common nodes and the connection failure is not considered. Concrete slab is fully connected to the upper flange of beams on the boundary and is continuous over the whole floor area. The external cladding in a particular storey is assumed to be attached to the columns and the beam below and is not attached to the upper beam. 
The benefits and drawbacks of implicit dynamic solver and explicit dynamic solver have been discussed in the companion paper. Generally, explicit solver is suitable for blast response analysis and implicit solver is appropriate for fire response analysis. In this example, explicit solver is used for both blast and fire analysis for the following reasons:

(1) A large amount of shell elements are involved in the FE modeling of this problem. When using implicit solver, the transpose of the stiffness matrix and solution of the equilibrium equation imposes huge requirement for computing resources.

(2) The response of the structure in fire is highly nonlinear, which makes the convergence of implicit solver very difficult. When the step size is very small, the implicit solver no longer possesses superiorities over the explicit solver.

In the explicit solver, the acceleration at any time can be directly calculated from the equilibrium equation

$$
\{\ddot{x}\}=[M]^{-1}\left(\left\{P^{n}\right\}-\left\{F^{n}\right\}\right)
$$

where $\{\ddot{x}\}$ is the acceleration vector, $[M]$ the mass matrix, $\left\{P^{n}\right\}$ is the body force and external force vector, $\left\{F^{n}\right\}$ is the internal force vector, and $\mathrm{n}$ is the numerical time step. The explicit update of the velocities and coordinates is given by

$$
\begin{aligned}
& \left\{\dot{\mathrm{X}}^{(\mathrm{n}+0.5) \square \mathrm{t}}\right\}=\left\{\dot{\mathrm{X}}^{(\mathrm{n}-0.5) \Delta \mathrm{t}}\right\}+\left\{\ddot{\mathrm{X}}^{\mathrm{n}}\right\} \Delta \mathrm{t} \\
& \left\{\mathrm{X}^{(\mathrm{n}+1) \Delta \mathrm{t}}\right\}=\left\{\mathrm{X}^{\mathrm{n}}\right\}+\left\{\dot{\mathrm{X}}^{(\mathrm{n}+0.5) \Delta t}\right\} \Delta \mathrm{t}
\end{aligned}
$$

As no iteration or convergence check is required, the computation time needed for each time step is almost constant and the total computation time to finish one analysis depends on the total analysis time and the size of time step, $\Delta t$. For this model to be analyzed on a computer with $3.0 \mathrm{G} \mathrm{CPU}$ processor and $1 \mathrm{G}$ memory, the time to complete each second of analysis time is about 1500 minutes. If the fire burning duration is to be analyzed in real time scale, it needs 750 hours to complete the analysis of a 30 minutes fire. Therefore, it is necessary to scale the burning duration so the computational time can be shorten without affecting the final result.

To study on the effect of time scaling, a steel beam with fixed ends loaded by lateral static loading and heated to $1000^{\circ} \mathrm{C}$ is considered. It can be seen from Figure 4 that the response of the beam in fire is not very sensitive to the rate of heating. Small difference in displacement results is observed when the rate of heating varies from $150^{\circ} \mathrm{C} / \mathrm{s}$ to $1000^{\circ} \mathrm{C} / \mathrm{s}$ for temperature less than $800^{\circ} \mathrm{C}$. Some variation in beam displacement is observed at the ends of the analysis (i.e., temperature $>800^{\circ} \mathrm{C}$ ) when steel has softened significantly and the cross section deformed rather significantly at high temperature. A static analysis is also performed by using ABAQUS and the deflection curve is shown in Figure 4. The static analysis terminates at $750^{\circ} \mathrm{C}$ due to convergence problem. However, for temperatures below $750^{\circ} \mathrm{C}$, results given predicted by the static analysis is very close to that by the explicit dynamic analysis. This study concluded that for fire analyses at high temperature $(>$ $800^{\circ} \mathrm{C}$ ) which usually involves significant cross section deformation (local buckling or distortional buckling), the rate of heating may be scaled up to $250^{\circ} \mathrm{C} / \mathrm{s}$. At low temperature $\left(<800^{\circ} \mathrm{C}\right)$, the rate of heating may be increased to $1000^{\circ} \mathrm{C} / \mathrm{s}$. In the analysis of the five storey building frame, the 30 
minutes duration of the parameter fire is scaled to 6 seconds. This is equivalent to an average heating rate of less than $200^{\circ} \mathrm{C} / \mathrm{s}$.

Temperature $\left({ }^{\circ} \mathrm{C}\right)$

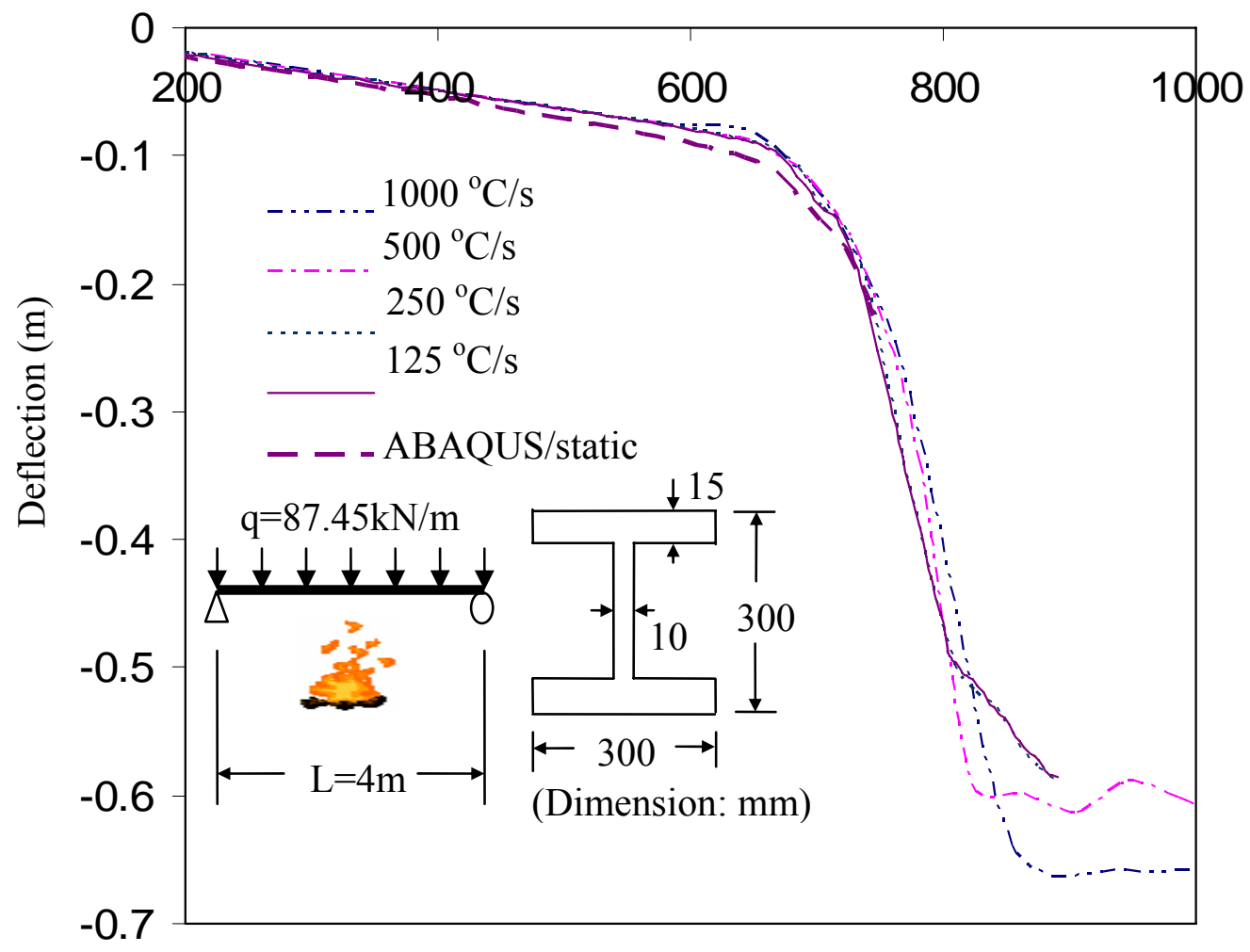

Figure 4. Effect of rate of heating on the deflection of steel beam

\subsection{Material Property}

For blast and fire analysis, the constitutive model should be able to capture 1) material hardening due to strain-rate effect, 2) material softening due to thermal effect and 3) material failure.

Steel is a high-strength, isotropic material with very good ductility. It can sustain extreme deformations before any sign of material failure. However, steel lose its strength when it is heated beyond to $400^{\circ} \mathrm{C}$. Degradation of the strength at elevated temperature is the major reason that leads to structural collapse in fire. Therefore thermal effect must be included and the elastic-plastic-thermal material model is chosen for structural steel. In the present study, the stress-strain curves for steel at elevated temperature is in accordance with EC3: Part 1.2 [4] as shown in Figure 5. 


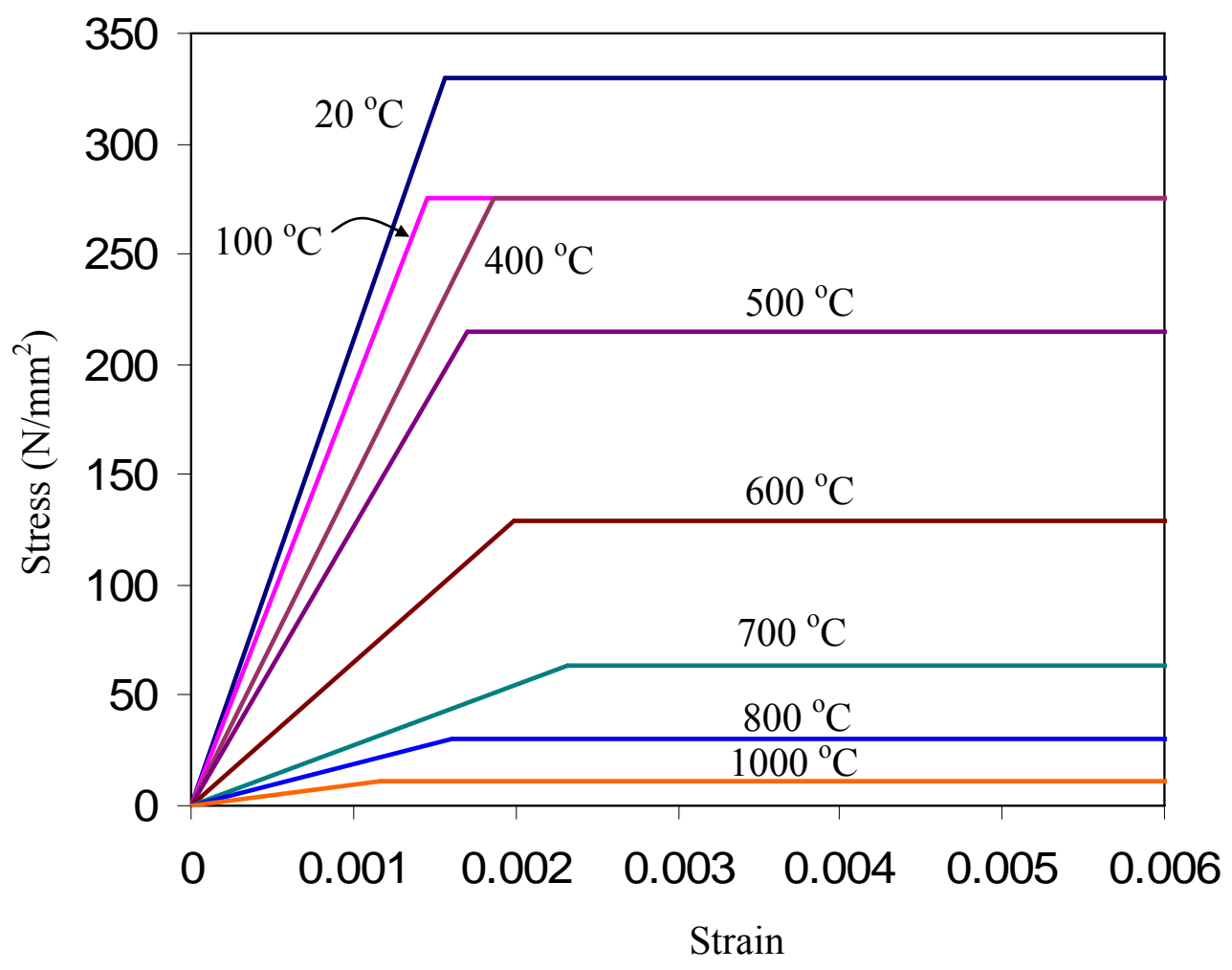

Figure 5. Constitutive model used for structural steel (CEN, 2001a)

To model the strain rate effect, the work by Soroushian and Choi [5] shows that the yield strength of steel can be enhanced by $20 \%$ to $50 \%$ at when the strain rate increases from $10^{-3} \mathrm{sec}^{-1}$ to $1 \mathrm{sec}^{-1}$. For simplified calculation, TM5-1300 (1990) recommends that the design strength of steel can be increased by $20 \%$ to consider the strain-rate effect under blast loading. For the ease of modeling, TM5-1300 [6] recommendation is adopted in the present analysis for modeling the strain rate effect on steel strength.

Concrete is a heat retardant material which has a relatively low conductivity as compared to steel. Heat transfer analysis shows that the maximum average temperature of the concrete slab is only slightly above $200^{\circ} \mathrm{C}$ in the fire compartments. The degradation of concrete strength and stiffness with temperature is therefore neglected and the nominal design strength of $24 \mathrm{~N} / \mathrm{mm}^{2}$ is used for C30 concrete. The effect of strain-rate is simply dealt with by amplifying the static yield strength with a factor

$$
\lambda=1+\left(\frac{\dot{\varepsilon}}{C}\right)^{\frac{1}{P}}
$$

where $\dot{\varepsilon}$ is the strain rate and $\mathrm{C}$ and $\mathrm{P}$ are two constant parameters depending on the types of material used. TM5-1300 [6] recommends the values of $\mathrm{C}=30$ and $\mathrm{P}=3.5$ for $\mathrm{C} 30$ concrete, and the strength enhancement factor $\lambda$ versus the strain rate is shown in Figure 6.

The masonry wall is removed in the fire analysis and the thermal effect is non-relevant for this material. The most critical feature for modeling the cladding is to propose a failure criterion that can simulate the cracking and destruction of the masonry wall. However, this phenomenon is too complicated for detailed consideration here and a simplified criterion based on the failure strain is defined. According to the work by Makovicha et al. [7], masonry wall panel may be considered as 
collapsed when the angle of the change of gradient of the bending line near the mid-span area exceeds the limiting value of $1^{\circ} \sim 2^{\circ}$. The failure of masonry wall is governed by either the maximum displacement or the maximum tensile strength being reached. For a masonry panel of dimension $2250 \times 2755 \mathrm{~mm}$ and thickness $65 \mathrm{~mm}$, the maximum displacement at failure was $50 \mathrm{~mm}$. This is equivalent to a tensile stress of $2.3 \mathrm{MPa}$ with an effective wall stiffness of $268 \mathrm{MPa}$. Dividing the stress by the effective stiffness gives a failure strain of 0.0084 . This failure strain value will be used as a criterion to define the failure of the masonry cladding in the present study.

So far no work has been conducted on the effect of strain rate on the strength of masonry. According to the work by Grote et al.[8], mortar is extremely sensitive to strain rate applied in the range of $10^{-3} \mathrm{sec}^{-1}$ to $1170 \mathrm{sec}^{-1}$. It is expected that the design strength of masonry wall will also be significantly enhanced in high strain rate due to blast loading. In the present study, the material model for concrete is used for masonry to approximate the strain-rate effect.

\section{4. $\quad$ BLAST ANALYSIS}

\subsection{Calculation of the Blast Pressure}

Assume a mid-size car explosive is detonated at $5 \mathrm{~m}$ from the outer surface of the building. From the terrorist bomb summary data provided by Bangash [9], the TNT equivalent weight of the explosive is assumed to be $1000 \mathrm{~kg}$. The blast pressure acting on a particular point on the external cladding is calculated as the reflected blast wave pressure at that position. The maximum pressure is at the point with shortest distance to the charge position. The blast pressure for a point at $5 \mathrm{~m}$ away from the detonation position may be calculated as follows:

(1) The distance of this point to the detonation is

$$
R=5 \mathrm{~m}=16.404 \mathrm{ft}
$$

The scaled distance is

$$
Z=\frac{R}{W^{1 / 3}}=\frac{16.404}{2203^{1 / 3}}=1.26 f t \cdot l b^{-\frac{1}{3}}
$$

where $\mathrm{W}$ is the TNT equivalent weight of the explosive in $\mathrm{lb}$.

(2) According to the scaled distance $\mathrm{Z}$, the incident overpressure $\mathrm{P}_{\mathrm{s}}$ (psi) and scaled arrival time of the wave $\frac{t_{a}}{W^{1 / 3}}$ can be obtained from TM5-1300 [6] as $\mathrm{P}_{\mathrm{so}}=707.5 \mathrm{psi}$ and $\frac{t_{a}}{W^{1 / 3}}=0.110 \mathrm{~ms} \cdot \mathrm{lb}^{-\frac{1}{3}}$. The arrival time is $1.43 \mathrm{~ms}$.

(3) The reflected over-pressure is simply a scale of the incident over-pressure by the amplification factor $\mathrm{C}_{\mathrm{r}}$. At this point, the incident wave is perpendicular to the wall, therefore, $\alpha=90^{\circ}$. The reflected wave amplification factor can be calculated as $\mathrm{C}_{\mathrm{r}}=8.13$, that is, $\mathrm{P}_{\mathrm{so}}=5752$ psi. The reflected impulse is obtained from $\frac{I_{r}}{W^{1 / 3}}=195.55 \mathrm{psi} \cdot \mathrm{ms} \cdot \mathrm{lb}{ }^{-\frac{1}{3}}$, or $I_{r}=2544.5 \mathrm{psi} \cdot \mathrm{ms}$ 
(4) The shape of the reflected pressure can be approximated by triangular with zero rise time and the duration of the blast pressure is

$$
t_{0}=\frac{2 \times 2544.5}{5752}=0.885 \mathrm{~ms}
$$

Figure 7 shows the variation of the blast pressure on the front wall surface with a change of the distance $\mathrm{R}$ from the detonation source. With increase of distance, the peak pressure is decreased rapidly and the duration of the blast pressure is increased moderately.

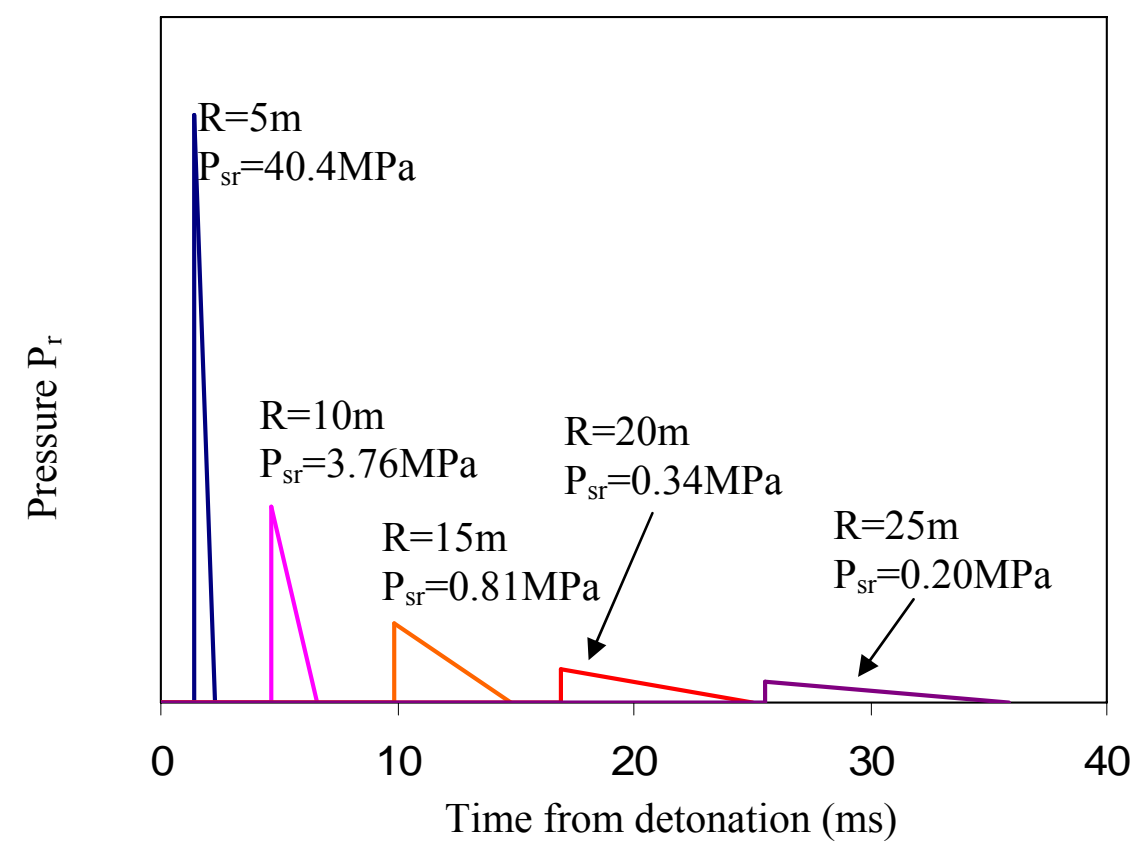

Figure 7. Variation of the blast pressure with distance to the charge position

\subsection{Structural Behaviour in Blast Load}

Comparing Figure 1 indicating the location of explosion with Figure 7 shows that the blast wave covers the whole structure in $50 \mathrm{~ms}$. It takes a little more time for the structure to respond. The damaged shape of the structure in $0.5 \mathrm{~s}$ is shown in Figure 8 for the front view and Figure 9 from the side view. Three wall panels W1, W2 and $\mathrm{W} 3$ are knocked out from the frame and fly toward the inside of the building. The wall panel that is nearest to the explosion is endowed

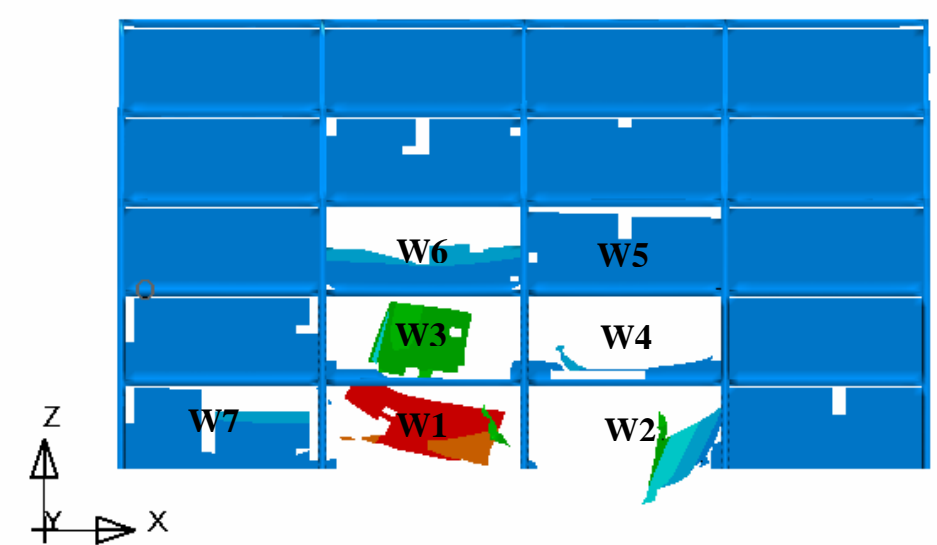

Figure 8. Front view of the structure after explosion with so much energy that it will fly to the back of the building with high speed provided that there is no obstruction. The other two panels can only reach grid line 3. Up to 1 s after explosion, four other panels W4, W5, W6 and W7 collapsed. But no initial speed is attained to cause any flying fragments. 
Effect of direct blast pressure acting on the concrete slab or direct impact from the damaged wall panels on the concrete slab are not considered in this analysis. The floor slab system is only subjected to lateral force from the blast pressure on the walls. The analysis results show no signs of failure on the slab system. The strong in-plane rigidity of the slab system ensures that the building deforms together in the lateral direction at each level. The lateral

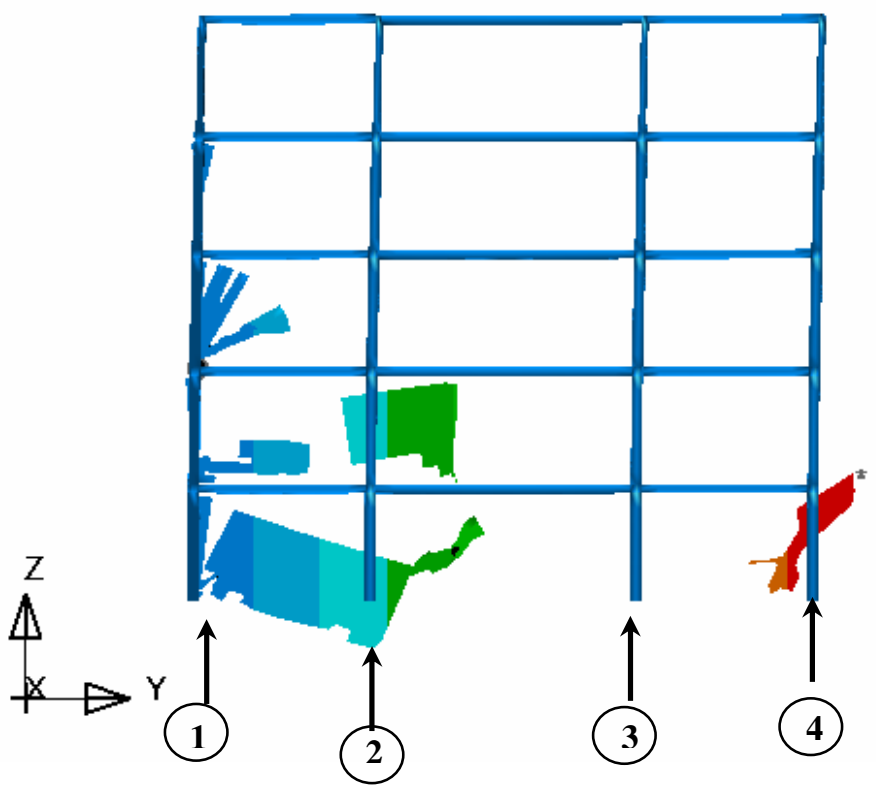

Figure 9. Side view of the structure after explosion displacements at each floor level are shown in Figure 10. The maximum inter-storey drift is about $0.12 \mathrm{~m}$ at the top level. At maximum deflection (corresponding to time $=0.6 \mathrm{~s}$ ), extensive yielding occurred at the upper and lower ends of the steel columns at each level.

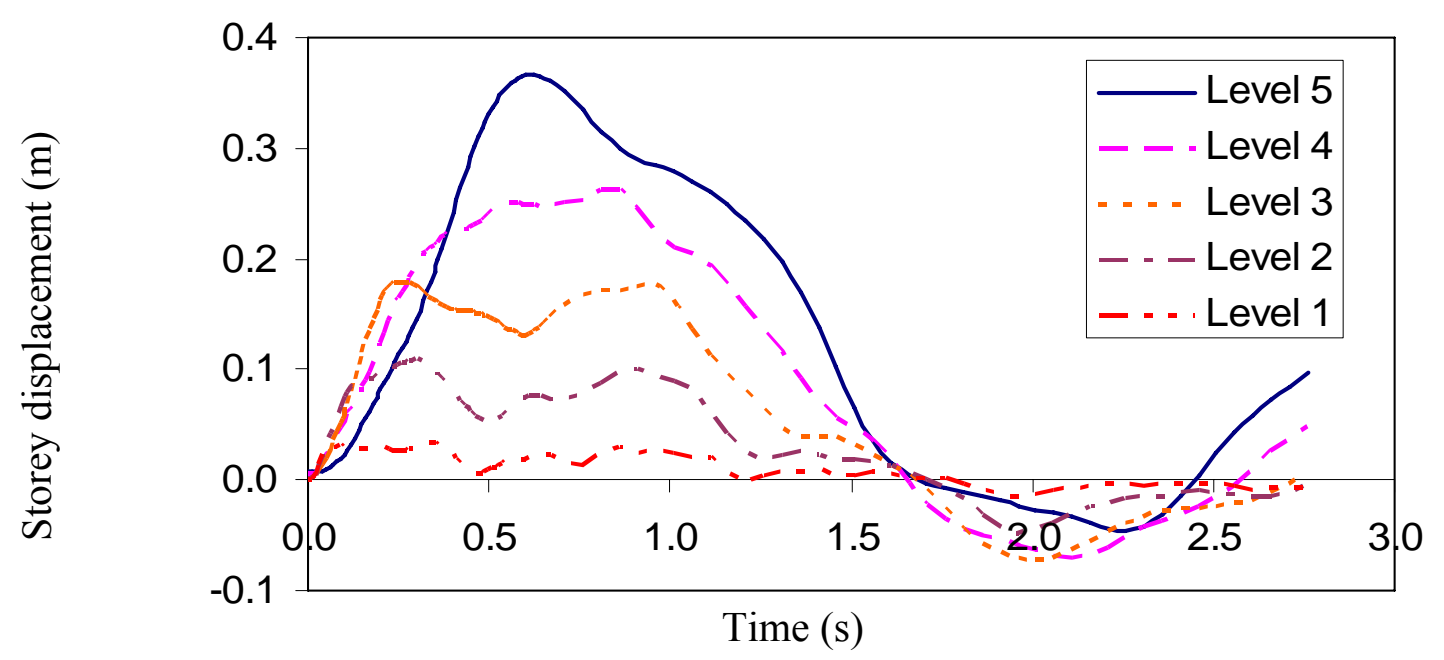

Figure 10. Lateral displacement of the frame at each floor level due to the blast load

Damages to the steel members are mostly concentrated to the columns at level 1 and 2 along grid line B1 and $\mathrm{C} 1$ as shown in Figure 11. These columns exhibit typical shear deformation mode near the upper and lower ends. The first wall panel failed within $10 \mathrm{~ms}$. The second and third one failed within $30 \mathrm{~ms}$. After the failure of these walls, the blast pressure acting the steel members is released immediately. Therefore, these columns are loaded with a very short duration. The maximum deflection of the steel columns is $60 \mathrm{~mm}$ for $\mathrm{C} 1$ at level 2. The deformed columns remain standing and supporting the vertical loads. The steel beams are restrained by the floor system at their upper flanges and very little damage is observed. The steel beams nearer to the blast positions have 
obvious distortion at the lower flanges. The beam nearest to the blast position at level 2 is blown upward and deflected by about $60 \mathrm{~mm}$ at the mid-span.

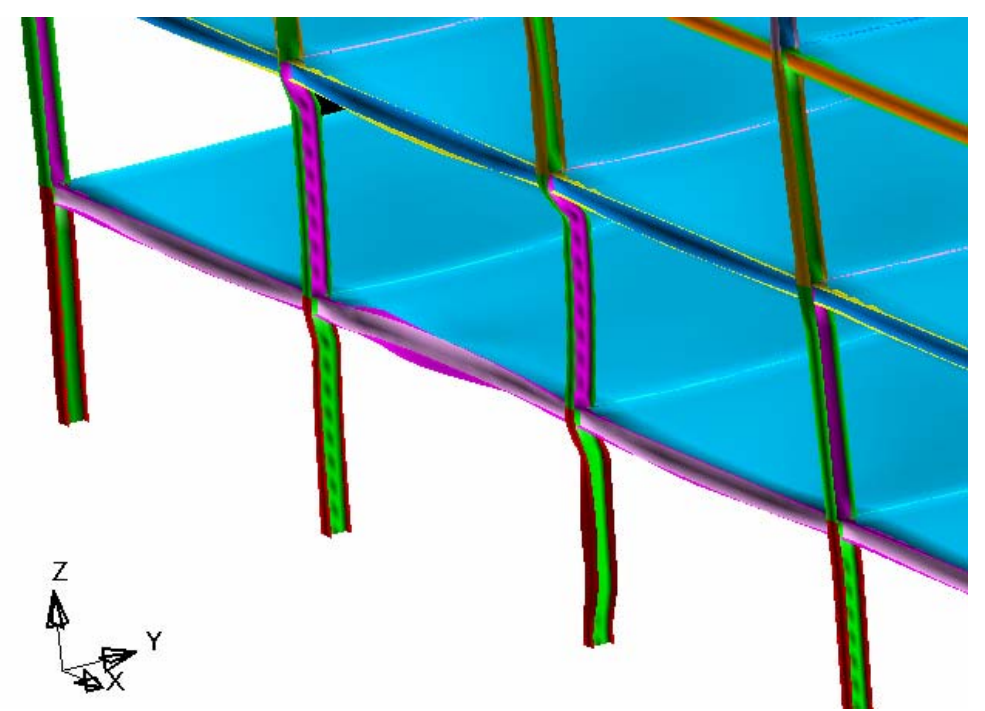

Figure 11. Shear deformation at the column ends and distortional deformation of the steel beams at 1.6 seconds after blast detonation

In general, damages caused by the blast load are limited to the cladding systems. Steel beams and floor slab system are subjected to minor local damages. Damage to several columns does not impose any threat to the overall stability of the building and there is no obvious downward movement of the floor system.

\section{SUBSEQUENTIAL FIRE ANALYSIS}

In this section, the devastating effect from the blast loading will be discussed and the fire resistance of the damaged building will be assessed.

\subsection{Effect of Blast on Fire Protection System}

Damage on active and passive fire protection system caused by blast load or fragmentation impact is very difficult to assess quantitatively because little information is available from the literature. For a reliable assessment, the manufactures of such systems should be consulted or tests should be carried to evaluate their performance in blast. In the present study, the following assumptions are made:

(1) At the ground floor level, the compartment wall separating Comp1 and Comp 2 will be impacted by the flying masonry bricks. It is required by EC1: Part 1.2 [1] that fire walls should resist a minimum horizontal impact load with a design energy of $3000 \mathrm{Nm}$. From the blast analysis results, the speed of the wall panel fragment reaching the compartment wall is about $45 \mathrm{~m} / \mathrm{s}$. The impact energy is equivalent to $437.4 \mathrm{kN} / \mathrm{m}$, which is far exceeding the designed resistance. Therefore, it may be assumed that the fire wall fails due to the impact. Therefore Comp 1 and Comp 2 can be combined to form a single fire compartment with a bigger burning space. At level 2 and level 3, the flying wall did not reach the compartment wall and the integrity of the wall is not breached. 
(2) The active fire fighting facilities such as fire alarm system, water sprinkler system, etc. are conservatively assumed not to be functional after blast.

(3) Due to the failure of the external cladding, fire is assumed to be ignited at the ground floor and it spreads to the upper floor levels. Considering the damaged shape of the claddings shown in Figure 7, fire is assumed to spread from level 1 to level 2 and then to level 3 . The higher floor level is assumed to be ignited when the temperature of the lower floor level reaches $700^{\circ} \mathrm{C}$.

(4) The damage to the passive fire protections covering the steel members are assessed based on the flying distance of the wall fragments. All the front columns that are directly exposed to blast pressure are assumed to have their fire protection completely removed. Considering the flying distance of the fragments, members that are within the reach of the flying fragments are assumed to lose half of their fire protections. Those members that are out of reach of the fragmentations are assumed to remain intact. According to this principle, the state of the steel members from level 1 to level 3 for the left part of the building are shown in Figure 12.

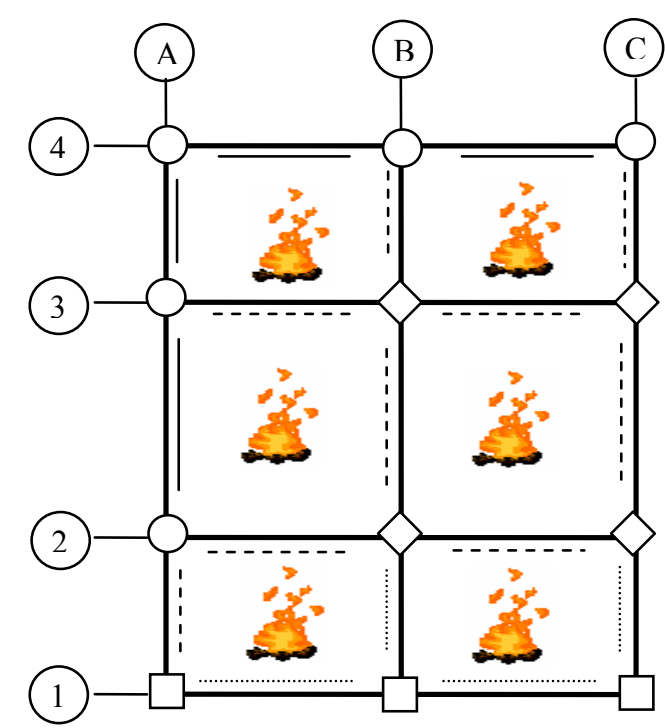

Level 1

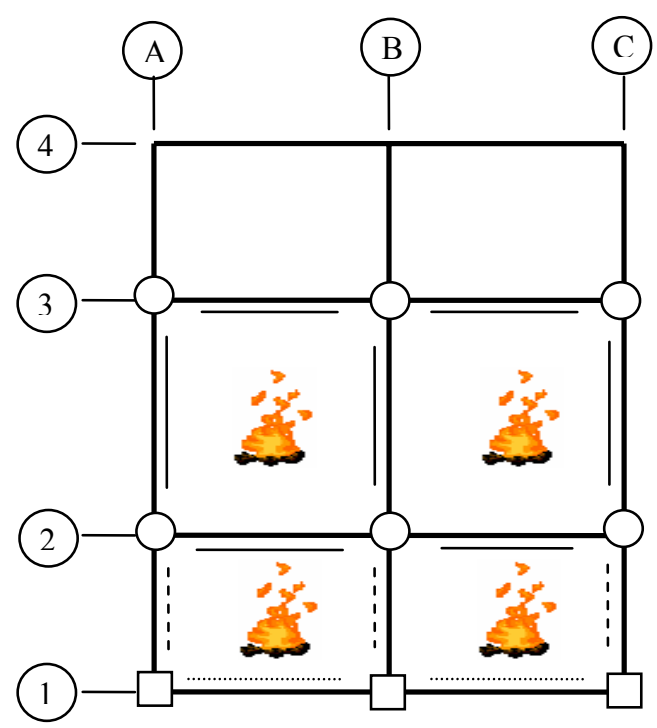

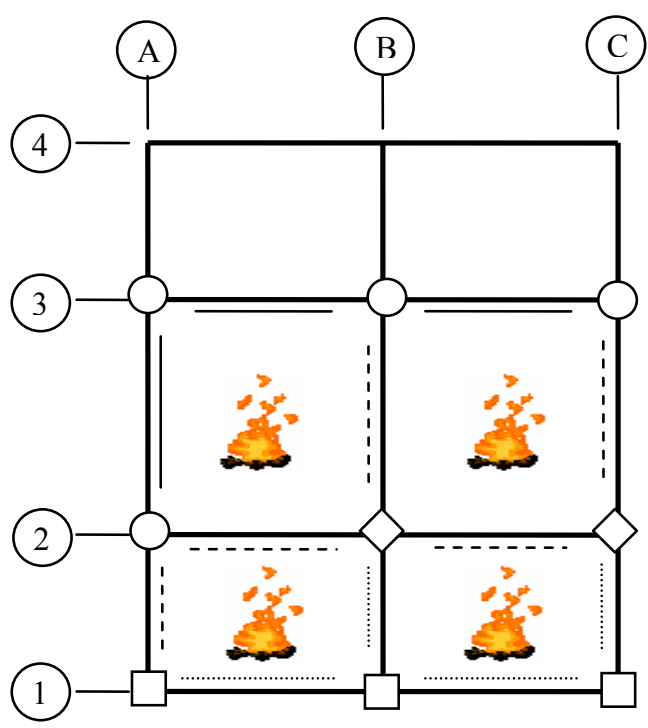

$\underline{\text { Level } 2}$

Symbols:

Column fire protection damaged

$\diamond$ Column fire protection partially damaged

Column fire protection undamaged

Beam fire protection damaged

Beam fire protection partially damaged

Beam fire protection undamaged

Level 3

Figure 12. Blast damage to passive fire protection 
The design fire model will be different from the design fire for the originally undamaged building due to the change of the parameters such as the fire load, fire compartment geometry, ventilation, etc. In the present study, the following changes are made in calculating the design fire in the fire compartment:

(1) when calculating the fire load, the effect of active fire fighting measure is set to $\delta_{n}=1.0$ instead of 0.6 so that the design fire load is enlarged by 1.67 times;

(2) At the ground floor, Comp 1 and Comp 2 merged into one big compartment with floor area equal to $378 \mathrm{~m}^{2}$;

(3) The opening area to the fire compartment is increased due to the collapse of the external walls.

After considering all the above factors, a new design fire curve for the ground floor and the upper floor levels are recalculated as shown in Figure 13. The fire curves are very close to each other. This is because the parametric fire curves for both compartments are fuel controlled and the there is little difference in the fire load for different floor levels. By assuming that fire will spread from the lower level to the upper level when the temperature of the lower level reaches $700^{\circ} \mathrm{C}$, it takes only 3 minutes for the fire at the ground floor to spread to the second level. The spread of fire is simulated by the different timing of fire curves shown in Figure 14. Comparison of the original fire curves in Figure 3 and the new fire curve in Figure 13 seems to indicate that fire in the damaged structure will become less severe despite the increase of the fire load. This is because when the opening area is increased, the fire becomes fuel controlled, the room fire is rapidly burnt out and heat is dissipated through the opening.

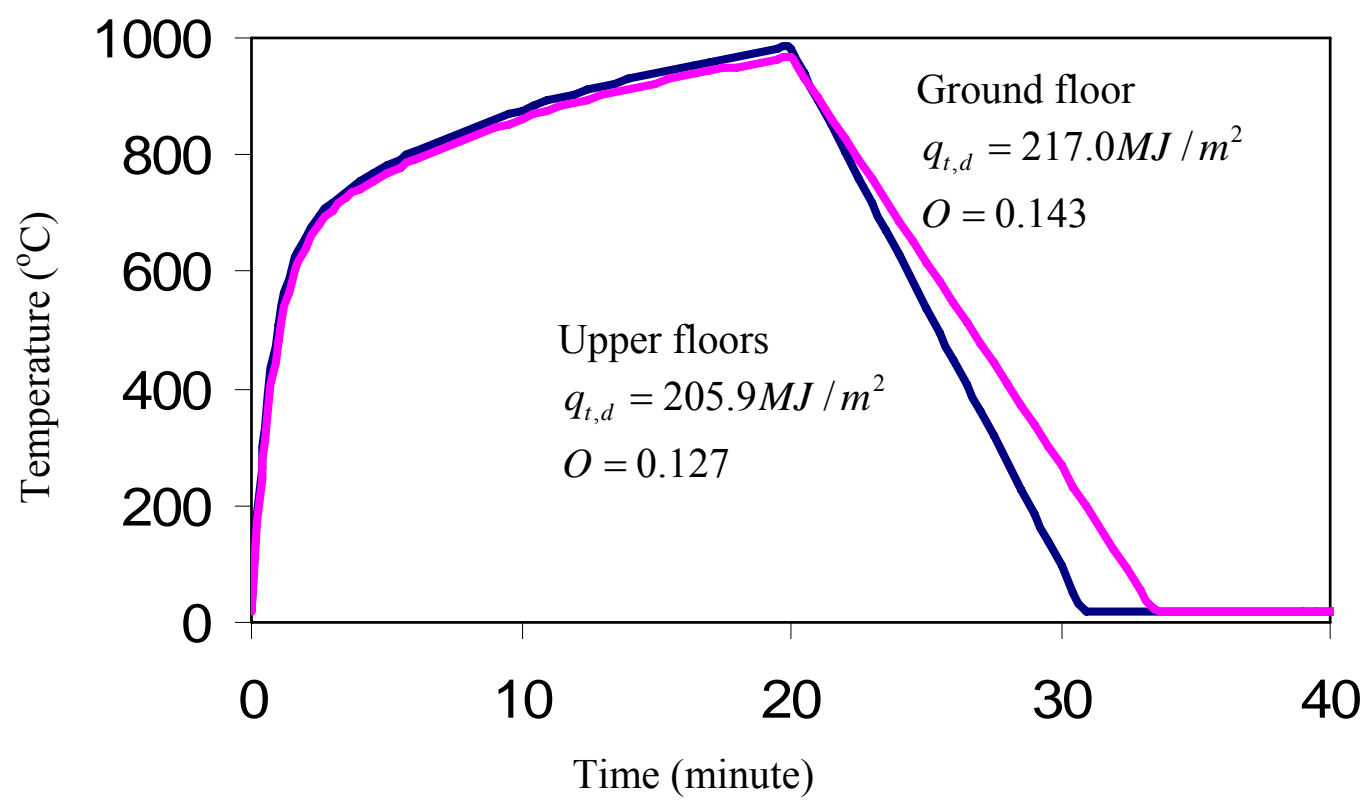

Figure 13. Design fire models for the building after blast 


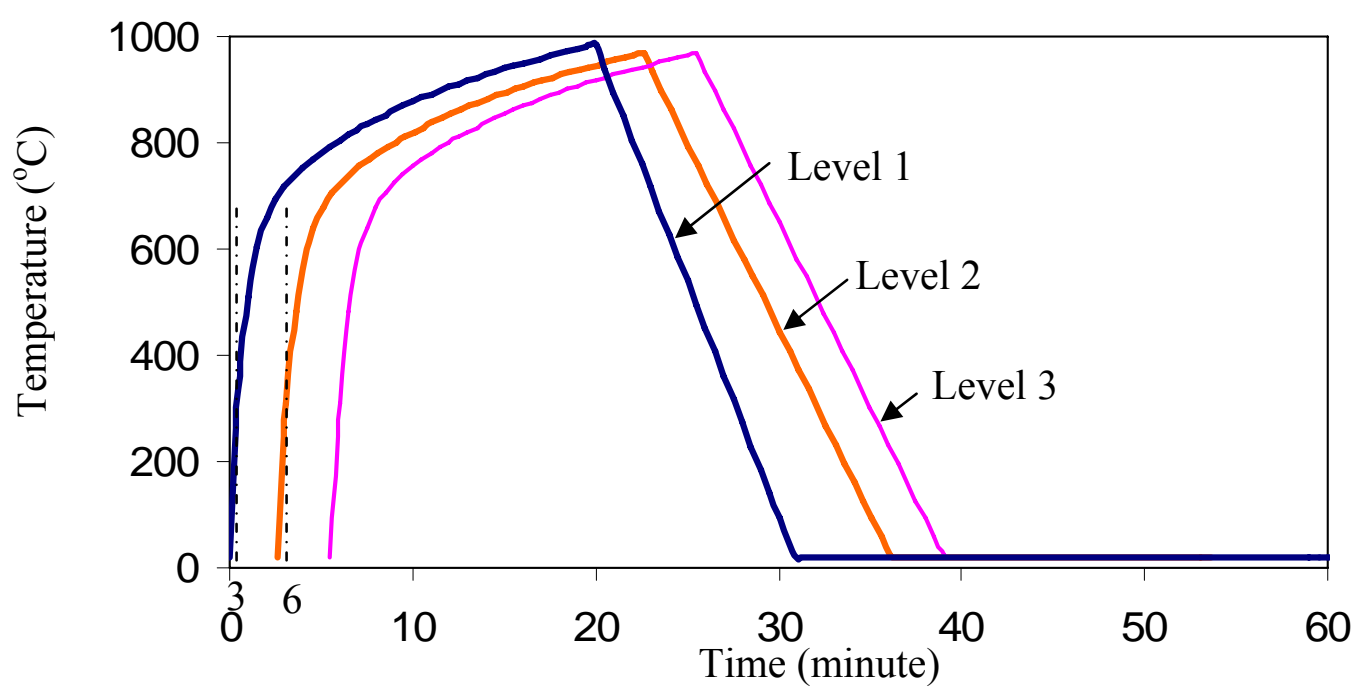

Figure 14. Spreading of fire from level 1 to level 3

\subsection{Response of the Damaged Structure in Fire}

According to the state of passive fire protection shown in Figure 12 and the design fire curves shown in Figure 13, the temperatures of the steel members in fire can be calculated from the incremental method recommended by EC3: Part 1.2 [4]. The approximate temperature development for beams and columns with fire protection undamaged, half damaged, and totally damaged are shown in Figure 15 and Figure 16. The temperature of steel members without any fire protection could be heated up to $1000^{\circ} \mathrm{C}$ in 20 minutes. Refer to Table 2 where the limiting temperatures of all the members are below $800^{\circ} \mathrm{C}$, it is expected that those members with their fire protection totally damaged after the blast will fail in fire.

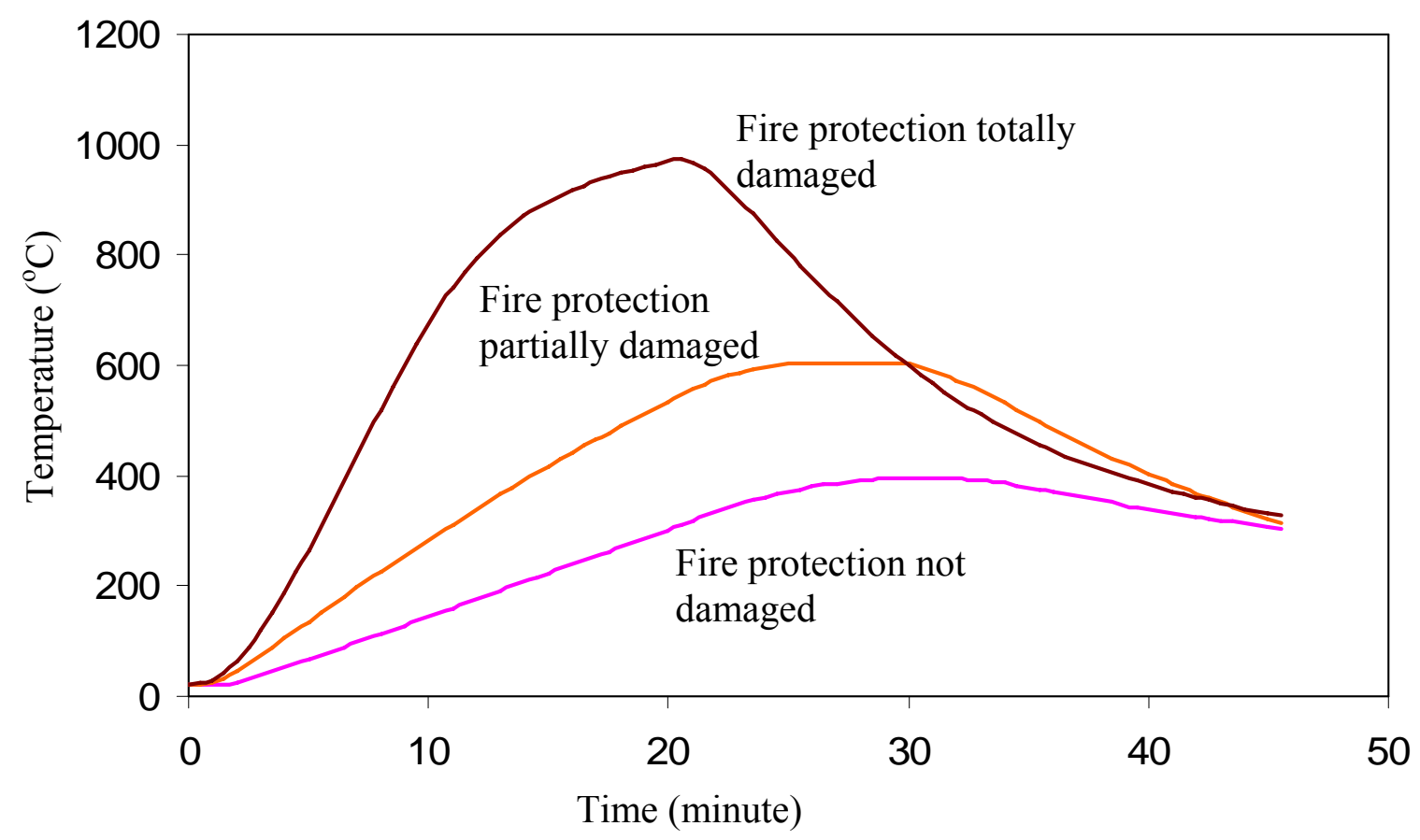

Figure 15. Temperature-time curves for steel beams in fire 


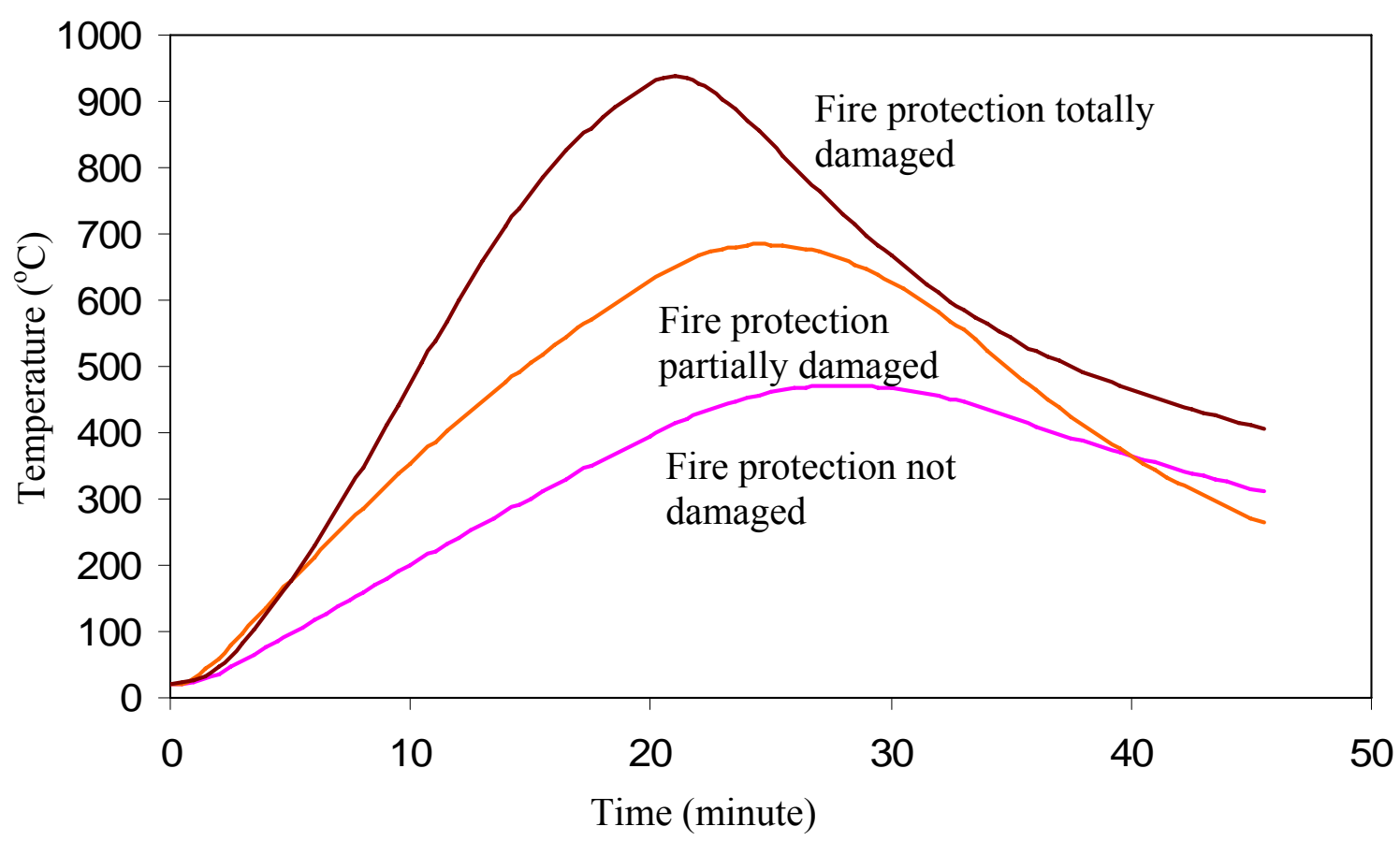

Figure 16. Temperature-time curves for steel columns in fire

The response of the structure in fire can be divided into several stages and the typical deformed shape of the building at each stage is displayed in Figures 17-19. The first stage is for heating time at 14 minutes, in which the deformed shape of the building is characterized by the large deflection of the beam and the slabs. With the increase of temperature, both the stiffness and the yield

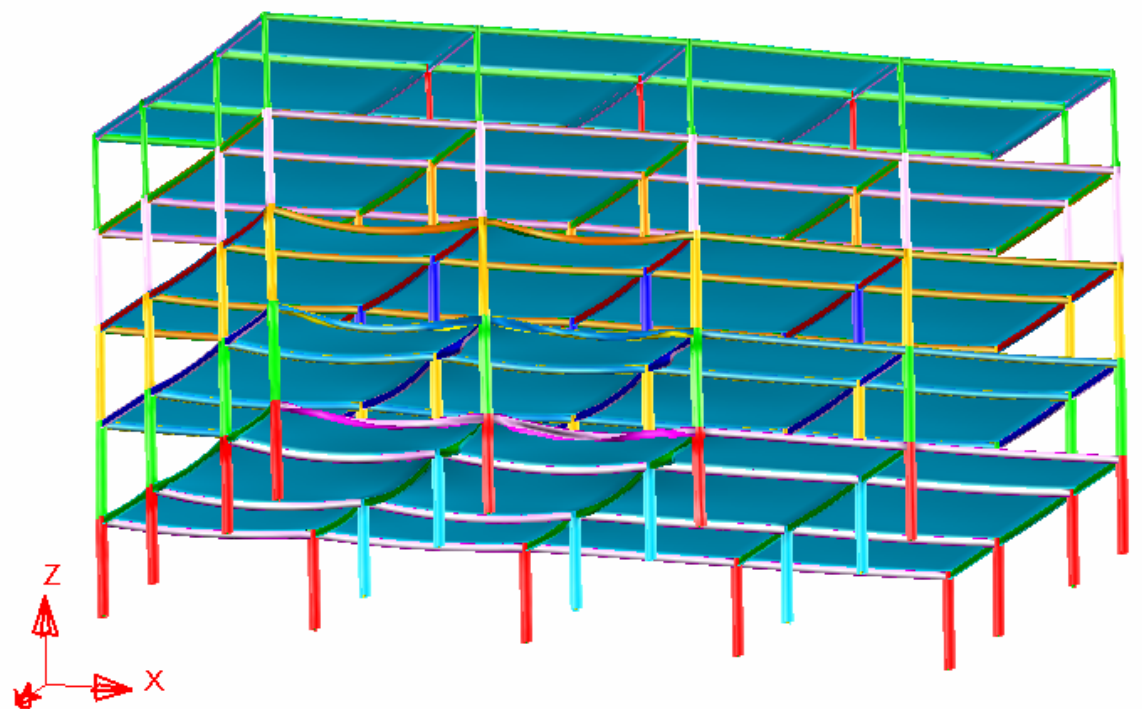
strength of the steel beams decrease and their deflections are increased. Although the degradation of concrete strength is not considered, the total deflection of the slab increased significantly due to the deflection of the supporting beams at the edges. Extensive local and torsional buckling of the steel beam section is observed in the fire compartments when the thermal expansions of the steel members are restrained both by the slab and the columns causing further deflection due to the secondary P- $\delta$ effect. 


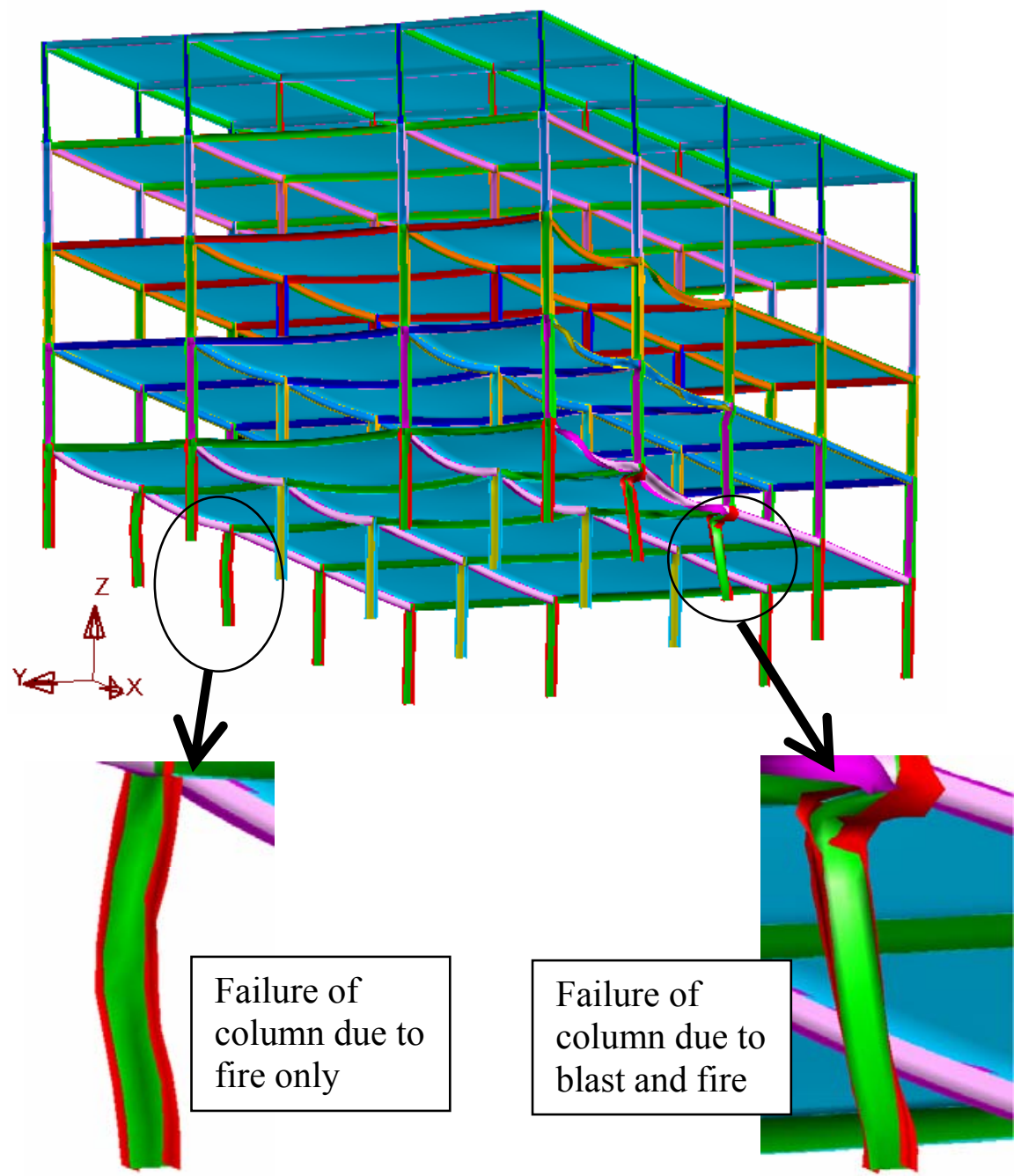

Figure 18. Buckling of the columns $(t=15$ minutes $)$

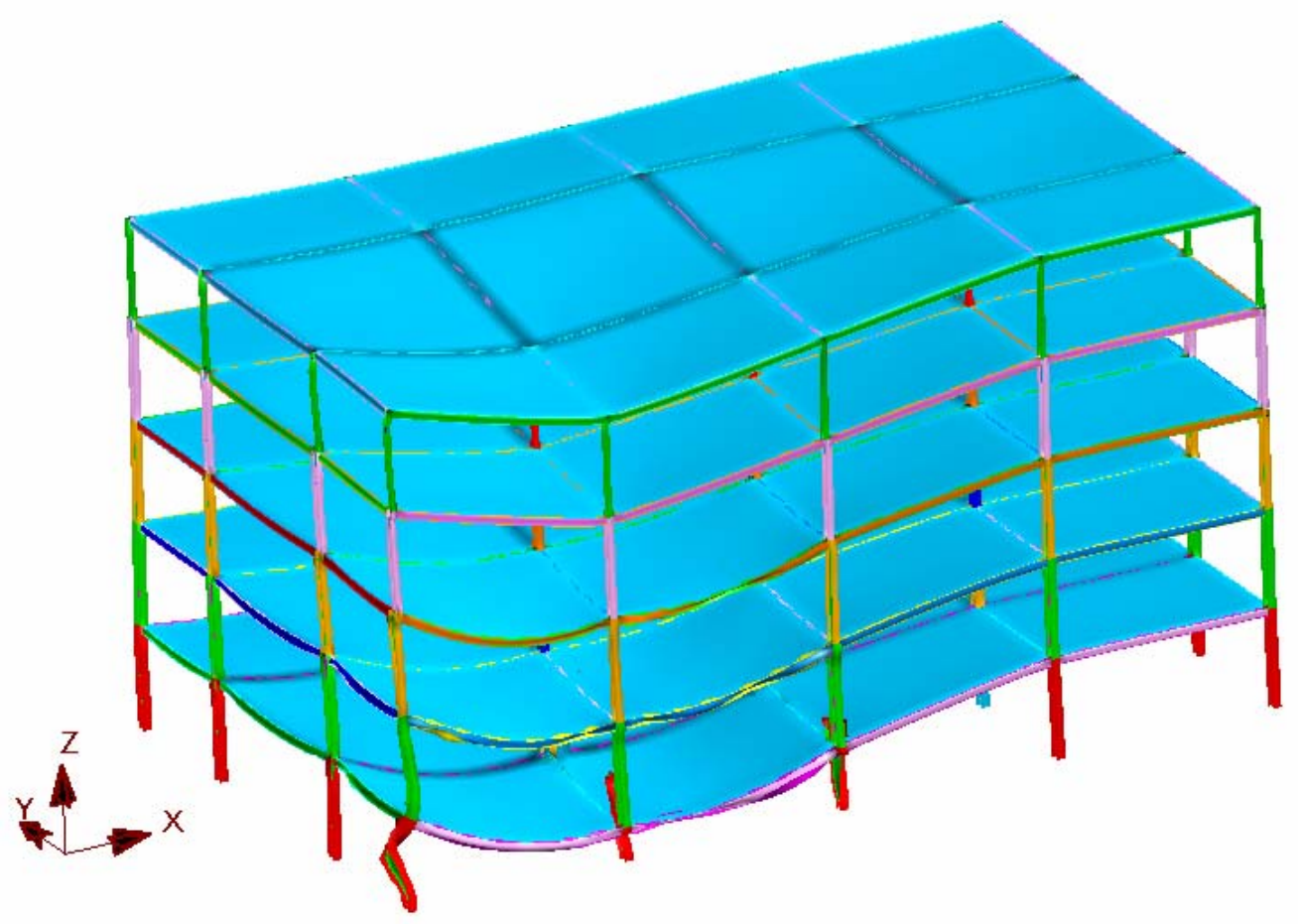

Figure 19. Collapsed shape of the frame $(t=18$ minutes $)$ 
After 14 minutes of burning, the columns in the fire compartment begin to show signs of buckling and initiated the second stage. At the ground floor, it was observed that Column A4 (column at the intersection of grid $\mathrm{A}$ and 4, etc.), B4 and C4 are unprotected columns by design, and the fire protection of $\mathrm{A} 1, \mathrm{~B} 1$ and $\mathrm{C} 1$ are totally damaged during the blast. These 6 columns are subjected to the same fire temperature, but columns $\mathrm{A} 1, \mathrm{~B} 1$ and $\mathrm{C} 1$ are initially deformed by the blast load. Therefore, when they are subjected to fire, column $\mathrm{B} 1$ and $\mathrm{C} 1$ show obvious buckling at 14.5 minutes, the failure position is at the top of the column as shown in Figure 17. Columns B4 and C4 did not fail until 15.5 minutes. The buckling mode is lateral deflection at the middle of the column. Comparing the behaviour of these two groups of columns, it may be concluded that the damage from the blast decreased the fire resisting time of the columns by about one minute or the fire resisting temperature by $47^{\circ} \mathrm{C}$.

Using the blast-fire interaction diagram proposed in the Part 1 of the companion paper can also predict similar results. The blast analysis gives the maximum deflection of the column to be about $60 \mathrm{~mm}$. The equivalent elastic deformation for this column is $25 \mathrm{~mm}$, which gives the plastic utilization factor to be 2.4. From the interaction diagram, a plastic utilization factor of 2.4 gives $T / T_{\max }=0.95$. The $T_{\max }$ for column $\mathrm{B} 1$ and $\mathrm{C} 1$ is given in Table 2 to be $707^{\circ} \mathrm{C}$. After damage from the blast effect, the limiting temperature is decreased to $672^{\circ} \mathrm{C}$. Blast will reduce the fire resisting temperature of the column by $35^{\circ} \mathrm{C}$.

After the failure of columns B1, C1, B4 and C4, the edge of the frame has undergone excessive vertical deflection, but the structure did not collapse because the vertical load on the buckled columns are transferred to the adjacent columns. Although the fire protection is partially damaged, the maximum temperature of the interior columns B2 and $\mathrm{C} 2$ are only $620^{\circ} \mathrm{C}$, less than the limiting temperature of $659^{\circ} \mathrm{C}$ shown in Table 2. From member design point of view, they should be safe in the fire. However, additional load transferred from the buckled columns caused the interior column to fail at about 18 minutes. The same happened to the corner column A1. With the loss of several columns, level 1 floor collapsed and initiated progressive collapse of other floors. The collapse mode is shown in Figure 18. The collapse time is 18.5 minutes after the ground floor is ignited.

In summary, this building, which is originally designed to be safe in fire only turned out to be unsafe in a fire after the incident of blast. By analyzing the behaviour of each structural component, the floor system provides good integrity and resistance to fire although it shows excessive deflections. Collapse of the structure is due to the failure of columns. This creates a chain reaction, which means failure of one column could bring failure to the adjacent and finally the lost of several columns in a storey will eventually bring down the upper floors in a very short time. The fire after the blast is not sever compared with the design fire without considering the blast effect. Therefore, the main reason for collapse is due to the loss of passive fire protections for some critical columns. When the ground floor columns failed, the upper floors will collapse progressively irrespective of their current state. In this case, fire spread from ground floor to upper floor does not impose more threat to the building or accelerate the collapse and therefore modeling of vertical fire spread needs not be considered in future for similar building of this category. 


\section{CONCLUSIONS AND RECOMMENDATIONS}

This paper analyzed the behaviour of a multi-storey steel-concrete composite building subjected to close-distance, medium-scale blast load and then followed by the fire attack. Finite element techniques and the constitutive models for strain rate and elevated temperature effects are discussed. Assessments are made on the effectiveness of active and passive fire protections according to the damaged state of the building after blast. The following conclusions can be drawn regarding the behaviour of the unbraced moment frames subjected to blast and fire:

(1) For steel framed buildings subjected to a small-scale, close-distance blast, some permanent deformation can be expected for members positioned very near to the blast location. The overall framework, if properly designed, can withstand the blast without collapsing. The floor system is basically undamaged providing continuity to all the columns in the storey level. However, the external cladding directly exposed to the blast wave may facture causing some flying fragments.

(2) The blast causes damage to both the active fire fighting system and passive fire protection system. For this case studied, damage to passive fire protection leads to the extremely high temperature on some critical members and this is the main reason attributed to the final collapse of the building.

(3) The damaged building possesses very little fire resistance and it collapsed after 18 minutes of burning. Initial damage from the blast changes the failure mode of columns and decreases the load carrying capacity of the columns. This effect can be approximately considered using the blast-fire interaction diagram.

The example studied in this paper shows the importance of considering the effect of fire after blast. It is concluded from the study results that to avoid the structural collapse in fire following blast, there are two key issues: one is to enhance the resistance of passive fire protection enclosures to impacts and the other one is limit the permanent deformation to steel members due to blast loading to avoid excessive loss of member resistance. 


\section{REFERENCES}

[1] European Committee for Standardization (CEN). Draft prEn 1991-1-2, Eurocode 1: Basis of Design and Actions on Structures, Part 1.2: Actions on Structures- Actions on Structures exposed to Fire. British Standards Institution, London; 2001.

[2] BSI. BS5950 Structural Use of Steelwork in Building: Part 1.Code of Practice for DesignRolled and Welded Sections. British Standards Institution, London, UK; 2003.

[3] Liew JYR, Ma KY. Advanced Analysis of Steel Framework Exposed to Accidental Fire. Second International Workshop. Structures in Fire, Christchruch, 2002:303-318.

[4] European Committee for Standardization (CEN). DD ENV 1993-1-2, Eurocode 3: design of steel structures, Part 1.2, General rules- structural fire design. British Standards Institution, UK; 2001.

[5] Soroushian P, Choi KB. Steel Mechanical properties at Different Strain Rates. Journal of Structural Engineering 1987;113(4):663-671.

[6] TM5-1300. Structures to Resist the Effects of Accidental Explosions. US Army Manual, November, 1990.

[7] Makovicha D, Makovicka Jr D. Failure of masonry under explosion effect. Structures under Shock and Impact VIII. Southampton, Boston: WIT Press, 2004:475-484.

[8] Grote DL, Park SW, Zhou M. Dynamic behavior of concrete at high strain rates and pressures: I. experimental characterization. International Journal of Impact Engineering 2001;25: 869-886.

[9] Bangash MYH. Prototype Building Structures: Analysis and Design. London: Thomas Telford, 1999. 